\title{
A DECISÃO DO TRIBUNAL CONSTITUCIONAL FEDERAL ALEMÃo SOBRE A CONSTITUCIONALIDADE DO TRATADO DE LISBOA
}

\author{
THE JUDGMENT OF THE GERMAN FEDERAL CONSTITUTIONAL COURT \\ REGARDING THE CONSTITUTIONALITY OF THE LISBON TREATY
}

\author{
Eleonora Mesquita Ceia*
}

RESUMO: Em 30 de junho de 2009 o segundo senado do Tribunal Constitucional Federal Alemão anunciou sua decisão sobre a compatibilidade do Tratado de Lisboa com a Constituição alemã. Por unanimidade os juízes decidiram a favor da constitucionalidade do Tratado. Apesar do resultado positivo, o Tribunal, na referida decisão, seguindo a jurisprudência fixada na sentença Maastricht de 1993, não só reafirmou os limites constitucionais da transferência de direitos de soberania à União Europeia, como também ampliou seu direito de controlar a constitucionalidade do direito da União. Ponto central da decisão é a exigência do fortalecimento das competências do Parlamento alemão em assuntos ligados à UE. O objetivo do presente artigo é examinar o conteúdo essencial da decisão do Tribunal Constitucional Federal Alemão sobre a constitucionalidade do Tratado de Lisboa, enfocando as principais teses do Tribunal acerca da evolução do processo de integração europeia.

PALAVRAS-CHAVE: Tribunal Constitucional Federal Alemão. Controle de Constitucionalidade. Tratados internacionais. União Europeia. Tratado de Lisboa.

ABSTRACT: On 30 June 2009, the Second Senate of the German Federal Constitutional Court announced its decision on the compatibility of the Lisbon Treaty with the German Constitution. Unanimously the judges decided for the constitutionality of the Treaty. Despite the positive result, in the Lisbon Case the Court, following its Maastricht jurisprudence, not only reiterated the constitutional boundaries of integration, but also expanded its right to review the constitutionality of the EU law. The main point of the decision is the requirement for strengthening of the German Parliament's competences in European Union matters. The goal of this paper is to examine the essential content of the German Federal Constitutional Court's decision on the constitutionality of the Lisbon Treaty, by focusing on the key theses of the Court regarding the evolution of the European integration process.

KEYWORDS: German Federal Constitutional Court. Judicial review. International treaties. European Union. Lisbon Treaty.

* LL.M. em Direito Europeu pelo Europa-Institut da Universidade de Saarland e Doutoranda em Direito da Faculdade de Ciências Jurídicas e Econômicas da Universidade de Saarland, Alemanha. 


\section{INTRODUÇÃ̃O}

Após a realização dos referendos em 2005 na França e nos Países Baixos pelos quais foi rejeitado o Tratado que estabelece uma Constituição para a Europa (ou Tratado Constitucional - TC), foi acordado por todos os Estados-membros que o formato do Tratado Constitucional - cujo fim era substituir os tratados constitutivos existentes - fosse abandonado e, como alternativa, decidiu-se impulsionar a conclusão de um tratado que introduziria emendas ao Tratado da União Européia (TUE) e ao Tratado que institui a Comunidade Européia (TCE).

Assim, o Conselho Europeu de Bruxelas de junho de 2007 convidou Portugal - país que assumiu a presidência rotativa da UE durante o segundo semestre de 2007 - a redigir um projeto de Tratado e a convocar uma Conferência Intergovernamental (CIG), cujo início ocorreu em julho de 2007. A redação final do texto foi apresentada na Cúpula Informal de Lisboa, em outubro de 2007. Em 13 de dezembro do mesmo ano, o denominado "Tratado de Lisboa" - conhecido também como "Tratado de Reforma" - foi assinado pelos Chefes de Estado e de Governo dos 27 Estados-membros da UE.

O Tratado de Lisboa substitui, portanto, o TC, mas o seu texto manteve muitas das inovações que constavam neste último. Entre as cláusulas mais importantes do Tratado de Lisboa, merecem menção: a conferência de personalidade jurídica própria à UE; a substituição do termo "Comunidade" por "União"; a nomeação do "Alto Representante para a Política Exterior e de Segurança Comum da UE"; a designação de um presidente estável da União; e a aplicação formal da dupla maioria a partir de 2014.

Logo após a sua assinatura, foi iniciado o processo de ratificação do Tratado de Lisboa. Para sua entrada em vigor, o tratado deveria ser ratificado por todos os 27 Estadosmembros da UE, de acordo com o procedimento previsto pelas respectivas Constituições nacionais. Em $1^{\circ}$ de dezembro de 2009 o Tratado de Lisboa entrou em vigor.

Em comparação com os tratados internacionais comuns ou tradicionais, os tratados constitutivos ou modificativos do processo de integração europeia - sendo o Tratado de Lisboa um deles - recebem tratamento diferenciado. A maioria das constituições nacionais europeias prevê exigências especiais para a conclusão dos tratados ligados à $\mathrm{UE}^{2}$. Ao lado disso, após sua entrada em vigor, tais tratados desfrutam de primazia sobre o direito nacional. Contudo, por causa de sua natureza de direito internacional convencional, os tratados europeus não estão isentos do controle jurisdicional de constitucionalidade.

\footnotetext{
1 Cumpre destacar que com a entrada em vigor do Tratado de Lisboa, o TCE passa a ser denominado de "Tratado sobre o funcionamento da União Européia" (TFUE). O TUE conservará a sua denominação.

2 Cf., por exemplo, o art. 23 da Lei Fundamental (Constituição alemã), o art. 93 da Constituição espanhola, o 20 da Constituição da Dinamarca e o art. 90 da Constituição polonesa.
} 
Com efeito, na jurisprudência das cortes constitucionais europeias são encontrados vários casos, nos quais o conteúdo do direito primário da União - isto é, dos tratados constitutivos ou modificativos - é controlado com parâmetro na Constituição nacional. O Tratado de Lisboa serve como exemplo. Sua compatibilidade com o texto constitucional nacional foi verificada em vários países ${ }^{3}$, inclusive na Alemanha.

A sentença do Tribunal Constitucional Federal Alemão (TCFA) de 30 de junho de 2009 sobre a constitucionalidade do Tratado de Lisboa ("decisão Lisboa") merece destaque. A jurisprudência do TCFA relativa ao direito da União exerce importante papel de referência sobre as demais cortes constitucionais europeias. Neste contexto, vale lembrar a clara influência da jurisprudência "Solange" do TCFA na Declaração Nr. 1 do Tribunal Constitucional Espanhol de 13.12.2004 sobre a compatibilidade do Tratado Constitucional com a Constituição espanhola. Da mesma forma, a influência da sentença Maastricht do TCFA de 12.10.1993 é evidente tanto na decisão do Supremo Tribunal dinamarquês de 06.04.1998, sobre a constitucionalidade do Tratado de Maastricht, como na decisão K 18/04 do Tribunal Constitucional polonês de 11.05.2005, sobre a constitucionalidade do Tratado de Adesão à UE.

A decisão Lisboa segue fundamentalmente a jurisprudência fixada na sentença Maastricht de 1993. Ela não só reafirma os limites constitucionais da transferência de direitos de soberania à UE, como também amplia seu direito de controlar a constitucionalidade do direito da União. Ponto central da decisão é a exigência do fortalecimento das competências do Parlamento alemão em assuntos ligados à UE.

O objetivo do presente artigo é analisar o conteúdo essencial da decisão Lisboa do TCFA, enfocando os seus efeitos sobre a participação da Alemanha no processo de integração europeia. Primeiramente, cumpre examinar a natureza do direito da União segundo o TCFA e identificar a fonte formal de validade dos tratados UE/CE dentro do ordenamento jurídico alemão, a fim de determinar o posicionamento do Tribunal sobre a relação entre o direito da União e o direito constitucional alemão.

Em seguida, o artigo trata do controle de constitucionalidade dos tratados europeus pelo TCFA. Antes da análise da decisão Lisboa, revela-se necessário apresentar as sentenças anteriores do TCFA sobre a constitucionalidade dos tratados europeus, visto que, como já indicado, o Tribunal segue a linha de argumentação estabelecida em sua jurisprudência precedente. Ao final, o trabalho resume e avalia de forma geral os principais pontos da decisão Lisboa.

3 Cf. a decisão Nr. 2007-560 DC do Conselho Constitucional francês de 20.12.2007; a decisão Pl. ÚS 19/08 do Tribunal Constitucional tcheco de 26.11.2008; a decisão Nr. 2008-35-01 do Tribunal Constitucional letão de 07.04.2009 e a sentença Nr. 125 da Corte Constitucional belga de 16.07.2009. 


\section{A NATUREZA DO DIREITO DA UNIÃO EUROPEIA SEGUNDO O TCFA}

Conforme a jurisprudência do TCFA, o direito da União tem primazia ${ }^{4}$ sobre o direito alemão, por força da autorização constitucional do Art. 23 I da Lei Fundamental (LF) e somente dentro de seus limites ${ }^{5}$.

Assim, ao contrário do Tribunal de Justiça da União Europeia (TJUE), o TCFA defende a posição, segundo a qual a natureza jurídica do direito da União não reside em sua autonomia, mas sim em seu fundamento no direito internacional público ${ }^{6}$. Por consequencia, é necessária uma ordem de execução por meio de uma lei de aprovação interna, para que o direito da União seja válido dentro do ordenamento jurídico alemão ${ }^{7}$.

De acordo com isso, a lei de aprovação constitui a fonte formal de validade e aplicabilidade dos tratados europeus no direito alemão. Em outros termos, ainda que ditos tratados sejam de hierarquia superior às normas internas, o TCFA condiciona a primazia do direito primário da União aos dispositivos constitucionais de recepção das normas de direito internacional público.

Com base nesse fundamento, o Tribunal se reserva o direito de controlar a aplicação do direito da UE. Os parâmetros de controle são os limites estabelecidos pelo

4 Importa assinalar que a primazia do direito da UE sobre o direito nacional diz respeito apenas à aplicabilidade da norma, e não à validade desta. Quer dizer, por razão do princípio da primazia do direito europeu, em caso de conflito com norma da UE, o direito nacional não torna-se nulo, mas somente inaplicável. A primazia do direito da União se estende à totalidade do ordemamento jurídico dos Estados-membros, ou seja, inclusive ao direito constitucional nacional (TJUE, Ac. 17.12.1970, Processo 11/70, "Internationale Handelsgesellschaft", Coletânea 1970, p. 1135). Como exemplo vale mencionar o caso "Kreil" (TJUE, Ac. 11.01.2000, Processo C-285/98, "Kreil/Bundesrepublik Deutschland”, Coletânea 2000, p. I-69), no qual o TJUE determinou que o então art. 12a IV 2 LF sobre o princípio geral de proibição de as mulheres prestarem um serviço com armas violava a igualdade de direitos conforme o Art. 2 da Diretiva europeia 76/207. Como resultado, a referida disposição da Constituição alemã teve de ser alterada. Cf. SCHWEITZER, Michael. Staatsrecht III. 9. ed. Heidelberg: Müller, 2008, p. 19-20.

5 O art. $23 \mathrm{LF}$ autoriza o legislador alemão a transferir direitos de soberania à UE, sendo para esta transferência de competências sempre necessária a aprovação do Conselho Federal (Bundesrat). Além disso, essa autorização constitucional é permitida apenas e na medida em que os princípios federativo, do Estado Democrático, Social e de Direito e o da subsidiariedade sejam resguardados. A remissão efetuada pelo art. 23 ao art. 79 II e III LF para a lei que aprove qualquer alteração dos Tratados constitutivos da UE, ou regras de natureza semelhante, representa a imposição de limites constitucionais rígidos à participação alemã no processo integracionista europeu. $\mathrm{O}$ art. 79 II e III regula as exigências quanto à aprovação e ao conteúdo de lei que altere a Lei Fundamental. Cf. STEIN, Torsten; VON BUTTLAR, Christian. Völkerrecht. 12. ed. Colônia: Heymann, 2009, S. 75-76.

6 Em sua decisão no caso "Costa/ENEL" o TJUE fundamenta a autonomia do direito da União com base no argumento, segundo o qual os tratados europeus - diferentemente dos tratados internacionais tradicionais criaram uma ordem jurídica "sui generis", a favor da qual os Estados-membros transferiram determinados direitos de soberania e cujos titulares de direitos não são apenas os Estados-membros, mas também seus cidadãos. Da autonomia do direito da União segue que questões sobre a relação entre o direito europeu e o direito nacional devem ser resolvidas segundo o direito da UE, e não pelas regras de direito internacional público. Cf. TJUE, Ac. 15.07.1964, Processo 6/64, "Flaminio Costa/ENEL", Coletânea 1964, p. 1269.

7 Essa tese está presente tanto na sentença Maastricht, como na decisão Lisboa, nos par. 190 e 343, respectivamente. 
art. 23 I combinado com o art. 79 III LF. Os obejtos sujeitos ao controle são as leis de aprovação dos tratados europeus. A seguir o controle do direito primário da UE exercido pelo TCFA será examinado em detalhes.

\section{O CONTROLE DE CONSTITUCIONALIDADE DOS TRATADOS EUROPEUS PELO TCFA}

Na Alemanha a jurisdição constitucional é especializada, concentrada no TCFA. O controle da constitucionalidade das leis é exercido sempre a posteriori, ou seja, somente depois da entrada em vigor da lei. Exceção a essa regra são as chamadas "leis de aprovação" (art. 59 II LF), que contêm o tratado internacional e o incorporam ao ordenamento jurídico interno.

Essa regra excepcional não é prevista expressamente em lei. Ela foi antes desenvolvida pela jurisprudência do TCFA e visa impedir o surgimento de conflitos entre as obrigações internacionais do Estado e o direito constitucional nacional. Quer dizer, essa regra especial tem a finalidade de evitar a situação na qual após a entrada em vigor da lei de aprovação e da ratificação do tratado e também de sua própria entrada em vigor no âmbito internacional, o TCFA declare inconstitucional o conteúdo do tratado indiretamente pela lei que o incorporou ao direito interno. Vale ressaltar que, caso essa situação ocorra, o governo alemão continuaria obrigado perante o direito internacional público, como parte contratante, porém o tratado e também a lei de aprovação não seriam aplicáveis no âmbito do ordenamento jurídico interno ${ }^{8}$.

A jurisdição do TCFA não se refere, por conseguinte, ao controle direto de constitucionalidade de tratados internacionais. Existe somente uma posição bem consolidada no sentido de que o controle indireto - o controle da lei que incorpora ao direito interno as normas contidas no tratado - é permitido.

As leis de aprovação de tratados internacionais podem ser controladas pelo TCFA - quando esse seja chamado a apreciar a controvérsia - inclusive quando o tratado ainda esteja em fase de elaboração. Neste caso, a ratificação do tratado pelo Presidente da República Federal é em regra suspensa, a fim de não obstruir o processo perante o TCFA.

O controle indireto de tratados internacionais - e, portanto, também dos tratados europeus - pelo TCFA pode ocorrer no marco de um processo contencioso entre órgãos constitucionais (Organstreit, art. 93 I Nr. 1 LF), em processos de controle abstrato de constitucionalidade (art. 93 I Nr. 2 LF), em processos de controle concreto de constitucionalidade (art. 100 I LF) e no âmbito de litígios entre a Federação e os Länder (art. 93 I Nr. 3 LF). Além disso, o TCFA há decidido reiteradamente que as leis que

8 Cf. STEIN; VON BUTTLAR, op. cit., p. 65. 
incorporam o conteúdo de tratados internacionais ao direito doméstico estão também sujeitas ao procedimento de recurso constitucional (Verfassungsbeschwerde, art. 93 I Nr. 4a LF), o qual tem a intenção de prover proteção efetiva dos direitos fundamentais aos cidadãos ${ }^{9}$.

Em vista do exposto, conclui-se que por meio do controle de constitucionalidade da lei de aprovação dos tratados europeus, o TCFA controla indiretamente também o conjunto do direito primário da UE. Em seguida serão examinadas as decisões do TCFA sobre a constitucionalidade dos tratados europeus. A exposição inicia-se com a análise da sentença Maastricht, na qual o TCFA se ocupou a fundo com o tema dos limites da abertura da Lei Fundamental à UE, como também com a questão da garantia dos direitos fundamentais dentro do processo de integração europeia.

\section{A JURISPRUDÊNCIA DO TCFA SOBRE A CONSTITUCIONALIDADE DOS TRATADOS EUROPEUS}

\subsection{A sentença Maastricht}

Na sentença Maastricht do TCFA de $12.10 .1993^{10}$ tratava-se de um recurso constitucional com base no art. 38 I 1 LF$^{11}$ contra a lei de aprovação nacional do TUE. O recurso contra o Tratado de Maastricht fundamentava-se na construção jurídica, segundo a qual o art. 38 I LF conjugado com o princípio democrático consagrado no art. 20 I e II LF e declarado inviolável pelo art. 79 III LF garante a cada cidadão o direito assegurado constitucionalmente de que âmbito da integração europeia competências substanciais sejam mantidas pelo Parlamento alemão.

Tal direito foi reconhecido pelo TCFA e o recurso constitucional contra a lei de aprovação do Tratado de Maastricht foi considerado como admissível ${ }^{12}$. Com isso, o

9 Cf. STREINZ, Rudolf. Europarecht. 8. ed. Heidelberg: Müller, 2008, p. 85.

${ }^{10}$ BVerfGE 89, 155. Esta decisão, como todas as outras do TCFA datadas anteriormente a 1998, estão disponíveis em <http://www.servat.unibe.ch/dfr > . Por outro lado, as decisões datadas a partir de 1998 são encontradas em < http://www.bverfg.de >. Uma versão impressa também está disponível, inter alia, na Coleção oficial das decisões do Tribunal.

${ }^{11}$ De acordo com o art. 38 I 1 LF os membros do Parlamento alemão são eleitos por sufrágio universal, direto, livre, igual e secreto. Essa regra garante ao cidadão o direito de participar do processo legislativo e influenciar seu exercício. Segundo o TCFA, o direito de voto nos termos do art. 38 I 1 LF constitui o elemento central do princípio democrático e equivale a um direito fundamental.

${ }^{12}$ Essa interpretação extensiva dos direitos democráticos do cidadão consagrados no art. 38 LF aplicada pelo TCFA - a qual acarretou a admissibilidade do recurso constitucional contra o Tratado de Maastricht - recebeu críticas da doutrina. Neste sentido, alguns autores argumentaram que a inclusão do princípio (jurídico-objetivo) democrático ao âmbito de proteção dos direitos subjetivos equivalentes a direitos fundamentais garantidos pelo art. 
TCFA deveria verificar - com parâmetro no art. 23 I LF - se o princípio democrático fora violado pela transferência de direitos nacionais de soberania à UE, na forma prevista pelo TUE. Uma violação estaria configurada, caso a legitimidade democrática conferida ao Poder Público alemão fosse "esvaziada" por meio da transferência de competências do Parlamento aos órgãos da UE.

As seguintes declarações do TCFA emitidas nesse processo merecem atenção especial: primeiramente o Tribunal destaca determinadas exigências com relação à legitimidade democrárica da UE. Segundo o TCFA, o princípio democrático não impede que a República Federal da Alemanha seja membro de uma organização supranacional. Porém, esse princípio pressupõe que uma legitimidade e influência oriundas do povo alemão sejam garantidas dentro dessa organização. Por este motivo, mesmo após a transferência de direitos de soberania, o Parlamento alemão deve permanecer com tarefas e atribuições de peso substancial.

Por trás desse argumento está a crítica do TCFA ao déficit democrático da UE. O Tribunal demonstrava receio com o fato de as competências de cunho legislativo caberem ao Conselho de Ministros, cujos membros são exclusivamente representantes dos governos nacionais. Para o Tribunal, o carácter democrático da União só poderia desenvolver-se se o Parlamento Europeu (PE) participasse mais estreitamente do processo decisório.

Assim, um verdadeiro processo democrático só seria possível - sob as condições da época - por meio da participação dos parlamentos nacionais. No estágio em que se encontrava o processo de integração não existiam, portanto, os requisitos necessários para que houvesse uma democracia operante dentro da UE. Por isso, o debate democrático deveria ocorrer nos Estados-membros e na esfera de seus respectivos órgãos nacionais de representação, a fim de que o princípio democrático não fosse desrespeitado ${ }^{13}$.

38 LF abre a possibilidade a cada cidadão de reivindicar no futuro, por meio de recurso constitucional, a violação desse princípio por toda lei de aprovação que diz respeito não somente à evolução da UE, como também à criação de qualquer organização internacional. Cf. KÖNIG, Doris. Das Urteil des Bundesverfassungsgerichts zum Vertrag von Maastricht - ein Stolperstein auf dem Weg in die europäische Integration? Zeitschrift für ausländisches öffentliches Recht und Völkerrecht (ZaöRV), v. 54, 1994, p. 26-29.

13 BVerfGE 89, 155, par. 184ss. Cf. também KÖNIG, op. cit., p. 37-39. Nesse contexto cumpre notar a decisão a decisão 2 BvR 635/95 do TCFA de 31.05.1995, cujo objeto era um recurso constitucional contra a lei de aprovação do tratado de adesão da Áustria, Finlândia e Suécia à UE. No recurso alegava-se que a composição do Parlamento Europeu (PE) contrariava o princípio constitucional da igualdade de representação eleitoral nos termos dos arts. 28 II 2 e 38 I 2 LF. Apesar do recurso não ter sido objeto de decisão, o TCFA declarou que a composição do PE condizia com a natureza da UE de associação de Estados soberanos e que, por conseguinte, a constituição do PE não podia ser avaliada com base nos critérios da Lei Fundamental aplicáveis para as eleições do Parlamento alemão. O TCFA conclui, afirmando que o PE, no estágio de integração da época, exercia apenas um mero papel complementar de apoio democrático à política da União. 
Em segundo lugar o Tribunal enfatiza, em diversas passagens da decisão, a independência e soberania da República Federal da Alemanha na qualidade de membro da UE $\mathrm{UE}^{14}$. O TCFA qualifica a União como uma "associação de Estados" (Staatenverbund) desprovida de competência - competência para alargar suas tarefas e atribuições. $O$ intuito do Tribunal com esta tese é de realçar que a condição de Estado da Alemanha deve perpetuar no âmbito do processo de integração europeia. Por conseguinte, a Lei Fundamental não permite a participação da Alemanha em um Estado Federal soberano europeu.

Em terceiro lugar o TCFA levanta a questão da proteção dos direitos fundamentais dentro da União. Ele reivindica o direito de controlar a aplicabilidade do direito derivado da UE na Alemanha sob uma estreita relação de cooperação com o TJUE. Em fazendo isto, o Tribunal reconhece a prioridade da competência de decisão do TJUE e restringe a sua própria competência a uma garantia geral do núcleo de direitos fundamentais exigido como indispensável pela Lei Fundamental ${ }^{15}$.

Ao lado da questão da proteção dos direitos fundamentais, o TCFA se ocupou com o respeito dos limites das transferências de competências. Aqui o Tribunal formulou uma segunda reserva de controle, na medida em que reivindica o direito de verificar - com parâmetro no direito constitucional nacional - se os atos jurídicos provenientes dos órgãos e instituições da UE cumprem os limites fixados na delegação dos direitos de soberania ou se os violam. O TCFA baseia seu direito de controle na tese, segundo a qual a lei de aprovação constitui a fonte formal de validade e aplicabilidade dos tratados europeus no direito alemão.

${ }^{14}$ O TCFA designa os Estados-membros da União como os "senhores dos Tratados", os quais podem, por isso, por meio de um ato de sentido contrário, decidir retirar-se da UE, fundada nesses mesmos tratados. Desta forma, os Estados-membros conservam sua posição de Estados soberanos (BVerfGE 89, 155, par. 190). Com isso, o TCFA funda um direito dos Estados-membros de retirada da UE. Um direito deste tipo é previsto pela primeira vez no Tratado de Lisboa (art. 50 TUE-Lisboa).

${ }^{15}$ Neste ponto o TCFA foi criticado por parte da doutrina por ter se afastado de sua jurisprudência “Solange". Vale recordá-la aqui brevemente: Na decisão Solange I (BVerfGE 37, 271) de 29.05.1974 o TCFA determinou que, enquanto a ordem jurídica comunitária não dispusesse de um catálogo de direitos fundamentais equivalente ao catálogo já previsto pela Lei Fundamental, todos os tribunais alemães estariam obrigados a não aplicar qualquer ato jurídico comunitário que conflitasse com os direitos fundamentais reconhecidos pela LF. Em sua decisão Solange II (2 BvR 197/83) de 22.10.1986 o Tribunal, contudo, reverte a sua posição anterior ao declarar que, enquanto o direito comunitário garantisse uma efetiva proteção dos direitos fundamentais e, equivalendo esta proteção àquela conferida pela LF, não seria mais justificável o controle de constitucionalidade dos atos jurídicos comunitários por parte do TCFA. Contudo, do ponto de vista da corrente majoritária, na sentença Maastricht o TCFA mantém seu posicionamento fixado na decisão Solange II. O próprio TCFA sublinha expressamente em sua decisão Bananas de 07.06.2000 que a sentença Maastricht representa uma continuação consequente de sua jurisprudência. Nesta decisão o Tribunal estabelece que o controle por parte dos tribunais nacionais da conformidade dos atos jurídicos comunitários com os direitos fundamentais, somente será admissível quando o ordenamento jurídico comunitário não seja capaz de assegurar um nível de proteção adequado conforme estipulado na decisão Solange II. Esta última decisão relativiza, portanto, de certo modo o latente conflito entre o TCFA e o TJUE. Cf. SCHWEITZER, op. cit., p. 33-35. 
Disso resulta que os atos jurídicos da UE que excedam os limites das transferências de competências estipulados na lei de aprovação alemã do TUE devem ser considerados como atos ultra vires. Logo, eles não produzem qualquer efeito jurídico para a República Federal da Alemanha e os órgãos estatais alemães estão impedidos por razões constitucionais de aplicar tais atos dentro da ordem jurídica nacional ${ }^{16}$.

Apesar da formulação de contundentes reservas de controle sobre o respeito dos limites das competências e dos direitos humanos no âmbito da União, como também a determinação de requisitos muito precisos à evolução da UE, o TCFA, como resultado do processo, rejeitou o recurso constitucional como infundado e declarou a compatibilidade do TUE com a Lei Fundamental. Logo, segundo a interpretação do TCFA, o conteúdo do Tratado de Maastricht - como estabelecido na lei de aprovação alemã - não viola o Art. 38 I 1 LF (BVerfGE 89, 155, 181).

\subsection{O Tratado de Amsterdã e o Tratado Constitucional}

Os limites estipulados para o TUE na sentença Maastricht valem também para os tratados modificativos posteriores. O Tratado de Amsterdã, porém, não suscitou na Alemanha qualquer problema de ordem constitucional. Em abril de 1998 o TCFA declarou um recurso constitucional contra a lei de aprovação do Tratado de Amsterdã como inadmissível (2 BvR 464/98). Neste caso, o Tribunal entendeu - conforme o § 93a da Lei do TCFA - que o recurso não apresentava qualquer importância fundamental de direito constitucional.

Com relação ao Tratado Constitucional, em 2005 o deputado do Parlamento alemão Peter Gauweiler encaminhou ao TCFA um recurso constitucional contra a lei de aprovação do referido tratado. Como o recurso proposto contra o Tratado de Maastricht, o recurso do deputado Gauweiler se baseava no art. 38 I LF. O autor argumentava que o Tratado Constitucional substituía a ordem constitucional da Lei Fundamental (2 BvR 839/05).

O recurso foi, contudo, resolvido pela supressão de seu objeto e, portanto, restando sem decisão. Isso porque após o resultado negativo do referendo realizado na França

${ }^{16}$ BVerfGE 89, 155, par. 188. Como na questão da proteção dos direitos fundamentais o TCFA foi criticado neste ponto por reclamar de forma não autorizada um direito último de decisão. A reivindicação do TCFA de um controle do direito da União com base no direito constitucional nacional colide não somente com o princípio da primazia do direito da UE sobre o direito nacional, como também com o monopólio de decisão do TJUE sobre o controle do direito secundário da União. Aqui vale assinalar a decisão Foto-Frost do TJUE de 22.10.1987, na qual o tribunal europeu determinou que as instâncias nacionais não são competentes para declarar nulos os atos jurídicos comunitários. Outra crítica à posição do TCFA merece atenção: caso outros tribunais dos demais Estadosmembros da UE seguissem a argumentação do TCFA, a uniformidade do direito da União poderia ser colocada em risco. Cumpre apontar que o TCFA em seu argumento sobre o respeito dos limites das transferências de competências não utiliza o conceito da "relação de cooperação" com o TJUE. Cf. KÖNIG, op. cit., p. 44-46 e SCHWEITZER, op. cit. p. 37. 
no final de maio de 2005 e nos Países Baixos no início de junho 2005 o processo de ratificação do Tratado Constitucional fora suspenso ${ }^{17}$.

\section{A DECISÃO LISBOA}

Essa decisão trata de dois processos contenciosos entre órgãos constitucionais e quatro recursos constitucionais apreciados conjuntamente pelo TCFA. Os autores são diferentes personalidades e grupos do cenário político alemão, incluindo membros do partido de esquerda "Die Linke" e o deputado conservador social-cristão Peter Gauweiler.

Os objetos dos respectivos processos são três atos, nomeadamente, a lei de aprovação alemã do Tratado de Lisboa e outras duas leis alemãs complementares ao referido tratado: a Lei que altera a Lei Fundamental (arts. 23, 45 e 93) e a Lei sobre a ampliação e o fortalecimento dos direitos do Parlamento Federal Alemão e do Conselho Federal Alemão em assuntos ligados à UE (Lei de Ampliação) ${ }^{18}$.

O ponto de partida é a violação alegada pelos autores do direito de voto do art. 38 I 1 LF, que, conforme a interpretação do TCFA, equivale a um direito fundamental. $\mathrm{O}$ argumento jurídico dos processos contra o Tratado de Lisboa é, portanto, igual ao levantado contra o Tratado de Maastricht. Os autores criticam essencialmente que a transposição do Tratado de Lisboa à ordem legal interna alemã transgride o princípio democrático, o postulado da soberania estatal, o princípio da separação dos poderes, a garantia da dignidade humana segundo a LF e os direitos do Parlamento alemão como órgão legislativo. Em vários dos processos havia pedido de medida cautelar. O Presidente Horst Köhler declarou então que assinaria os instrumentos de ratificação somente após a decisão do TCFA sobre a constitucionalidade do Tratado de Lisboa.

Baseado em sua teoria, segundo a qual cada cidadão alemão detém um direito democrático a um Legislativo dotado de poderes substanciais para determinar o destino do povo alemão, o TCFA examinou o Tratado de Lisboa minunciosamente e em sua totalidade. Três questões principais são identificadas na decisão: o nível de legitimação da UE (5.1), a preservação da soberania estatal da República Federal da Alemanha (5.2) e a conservação de responsabilidades e competências de peso substancial pelo Parlamento alemão (5.3).

${ }^{17}$ Além do recurso constitucional, o deputado Gauweiler apresentou ao TCFA um processo contencioso entre órgãos constitucionais conforme o art. 93 I Nr. 1 LF contra o Tratado Constitucional. Neste processo o autor alegava uma redução de seus direitos de participação como deputado do Parlamento alemão, dado que a transferência de direitos de soberania à UE como prevista no Tratado Constitucional representava uma erosão das competências do Bundestag. Cf. STREINZ, op. cit., p. 84-85.

${ }^{18} \mathrm{O}$ Tratado de Lisboa confere aos parlamentos dos Estados-membros direitos de participação direta frente aos órgãos da UE. As duas leis supracitadas, que acompanham o Tratado de Lisboa no ordenamento jurídico alemão, criam os requisitos legais internos necessários para o exercício desses direitos de participação pelo Parlamento alemão. As duas leis entram em vigor no dia em que o Tratado de Lisboa passa a vigorar para a Alemanha. 


\subsection{O nível de legitimação da UE}

Tendo em vista a extensão das competências transferidas à UE e o grau de independência dos procedimentos de tomada de decisão, o TCFA conclui que o nível de legitimação da União corresponde aos requisitos constitucionais do art. 23 I 1 LF, enquanto o princípio da atribuição de competências é assegurado em uma medida que vai além daquela prevista nos Tratados ${ }^{19}$.

Segundo o entendimento do Tribunal, com o Tratado de Lisboa o processo de integração segue evoluindo, mas a UE não alcança ainda qualquer configuração que corresponda ao nível de legitimação de uma democracia estatal ${ }^{20}$.

Na sentença Maastricht o TCFA prezou a contribuição do Parlamento Europeu à legitimação democrática da União e defendeu um aumento gradual do papel do PE dentro do processo de integração $0^{21}$.

Por outro lado, na decisão Lisboa, o TCFA avalia o papel do PE de forma muito mais crítica. Segundo o Tribunal, a legitimação democrática por meio do PE é limitada, devido aos contingentes de assentos dos Estados-membros resultantes da composição regressivamente proporcional prevista no art. 14.2 I frase 3 TUE-Lisboa. Para o Tribunal, em uma verdadeira democracia o peso de cada eleitor deve ser o mesmo, o que deve ser refletido em igualdade de participação no respectivo órgão parlamentar representativo.

De acordo com essa tese, o TCFA argumenta que o PE não pode ser reconhecido como um órgão parlamentar legítimo, visto que aos cidadãos dos menores Estadosmembros é concedida uma maior representação do que aos cidadãos das maiores nações. Logo, o Tribunal conclui que o PE não constitui um órgão de representação de um povo soberano europeu, mas sim um órgão supranacional que representa os povos dos Estados-membros da UE, no qual o princípio da igualdade eleitoral não encontra qualquer aplicação ${ }^{22}$.

O TCFA expõe que este déficit democrático não pode ser eliminado por elementos de democracia participativa e associativa presentes no Tratado de Lisboa, como, por exemplo, o fortalecimento da participação e transparência (art. 11 TUE-Lisboa) e o involvimento dos parlamentos nacionais (art. 12 TUE-Lisboa). Isso porque estes instrumentos têm apenas uma função complementar e não central para efeitos de legitimizar uma autoridade pública europeia. É interessante notar que é exatamente esse

${ }^{19}$ Cf. BVerfG, 2 BvE 2/08 de 30.06.2009, par. 275. Uma versão em língua inglesa da decisão está disponível em < http://www.bverfg.de/entscheidungen/es20090630_2bve000208en.html >.

${ }^{20}$ Ibid., par. 276.

${ }^{21}$ BVerfGE 89, 155, par. 185.

22 BVerfG, 2 BvE 2/08, par. 280ss. 
papel relativamente fraco e de natureza apenas complementar do $\mathrm{PE}$ a razão pela qual o TCFA considera esse órgão compatível com a LF23.

\subsection{A soberania estatal}

Uma das alegações dos autores contra o Tratado de Lisboa é a de que a UE evolui em direção à formação de um Estado federal, tendo isso como consequência a perda de soberania pela República Federal da Alemanha. Sobre este ponto o TCFA sublinha primeiramente a abertura da Lei Fundamental ao direito europeu (Europarechtsfreundlichkeit), afirmando que o objetivo de integrar a Alemanha em uma ordem internacional e europeia pacífica resulta do art. 23 I LF e do preâmbulo da Constituição alemã ${ }^{24}$.

Entretanto, o Tribunal acentua que a participação da Alemanha no processo de integração europeia deve obedecer aos limites da "identidade constitucional" 25 inalienável prevista no art. 79 III LF. Esta disposição é a chamada “cláusula de eternidade" que, segundo o TCFA, protege a soberania estatal. Assim, a integração da Alemanha em um Estado federal - e com isso a perda de soberania - exigiria que o povo alemão adotasse livremente uma nova constituição (art. 146 LF).

A Lei Fundamental não autoriza, por conseguinte, os órgãos que atuam em nome da Alemanha, por meio da entrada do país em um Estado federal, a ceder o direito de autodeterminação do povo alemão sob a forma da soberania da Alemanha segundo o direito internacional. Este passo é reservado apenas à vontade diretamente expressa pelo povo alemão. Em contraste com a sentença Maastricht, a decisão sobre o Tratado de Lisboa recusa explicitamente, portanto, a criação de um Estado federal europeu ${ }^{26}$.

Nesse sentido, o TCFA explica que de acordo com o art. 23 I LF a Alemanha participa do desenvolvimento de uma União europeia concebida como uma associação de Estados nacionais soberanos. Aqui o Tribunal fornece uma clara definição do conceito de Staatenverbund: este cobre uma estreita associação de longo prazo composta por Estados que permanecem soberanos, uma associação que exerce autoridade pública com base em

${ }^{23}$ Ibid., par. 262 e 294. TOMUSCHAT critica a posição do TCFA em considerar o PE como sendo uma instituição meramente marginal ao processo de integração. Para ele, é curioso discutir na presente era marcada pela globalização que uma democracia genuína possa somente existir dentro da estrutura do Estado-nação. Cf. TOMUSCHAT, Christian. The Ruling of the German Constitutional Court on the Treaty of Lisbon. German Law Journal, v. 10, 2009, p. 1261.

${ }^{24}$ BVerfG, 2 BvE 2/08, par. 225.

${ }^{25}$ O TCFA especificou a identidade da ordem constitucional listando princípios substanciais ou materiais, tais como democracia, o Estado de Direito, o princípio do Estado Social ou a substância dos direitos fundamentais elementares, os quais não são sujeitos a qualquer tipo de alteração. Ibid., par. 217.

${ }^{26}$ Ibid., par. 219 e 228. Cf. também WOHLFAHRT, Christian. The Lisbon Case: A Critical Summary. German Law Journal, v. 10, 2009, p. 1280. 
um tratado, cuja ordem fundamental é, contudo, sujeita exclusivamente à disposição dos Estados-membros e na qual os povos de seus Estados-membros, isto é, os cidadãos dos Estados, permanecem como sendo os sujeitos da legitimação democrática ${ }^{27}$.

O TCFA decide que a Alemanha permanece um Estado soberano com a entrada em vigor do Tratado de Lisboa ${ }^{28}$. Ele justifica sua decisão com base na definição de Jellinek de Estado, a qual compreende três elementos fundamentais: autoridade, território e povo. Segundo o TCFA, a UE não exerce uma autoridade territorial que substitui a da República Federal da Alemanha. Isso porque a autoridade estatal territorial continua a existir inalterada sob as condições da mobilidade transfronteiriça. A Alemanha seguirá também a ter um povo. A cidadania da UE é derivada unicamente da vontade dos Estados-membros ${ }^{29}$.

Com referência à decisão Maastricht o TCFA deriva do direito de voto do art. 38 I 1 LF a proibição da transferência de competência à UE para determinar a sua própria competência ("competência-competência"). Além disso, o Tribunal desenvolve a partir do art. 38 I 1 LF o princípio da responsabilidade parlamentária com a integração (Integrationsverantwortung) e um controle nacional de atos ultra vires - já presente na sentença Maastricht - e do respeito à identidade constitucional.

Enquanto não houver uma decisão direta da população, somente o Parlamento alemão pode assumir a responsabilidade com a legitimidade democrática. Logo, sempre quando os Estados-membros elaborarem o direito primário de modo que isso possa causar uma modificação desse direito sem um procedimento de ratificação ou de forma decisiva pelas instituições da União, incumbe às autoridades legislativas, ao lado do governo federal, uma responsabilidade especial no que diz respeito à participação. $\mathrm{Na}$ Alemanha, a participação nacional deve cumprir os requisitos do art. 23 I LF. Esta tese corresponde ao conceito inédito de "responsabilidade com a integração" (Integrationsverantwortung), que serve para justificar a expansão da interferência do Parlamento alemão na ação do governo em assuntos europeus. A "responsabilidade com a integração" representa um dos termos-chave da decisão Lisboa, uma vez que não fora utilizado na sentença Maastricht ${ }^{30}$.

O TCFA aponta que dentro da jurisprudência alemã deve ser possível, por um lado, impor a responsabilidade com a integração em caso de notórias transgressões dos limites quando a UE reivindicar competências e, por outro, preservar o núcleo inviolável

\footnotetext{
${ }^{27}$ BVerfG, 2 BvE 2/08, par. 229.

${ }^{28}$ Ibid., par. 275.

${ }^{29}$ Ibid., par. 344ss.

${ }^{30}$ O TCFA recorre ao termo "responsabilidade com a integração" em diversas passagens da decisão Lisboa. Veja ibid., par. 236, 238, 243, 245, 264, 272, 317, 319, 365, 375, 409, 411 e 415. Cf. também
} WOHLFAHRT, op. cit., p. 1282. 
da identidade constitucional da Lei Fundamental por meio de controle de identidade (Identitätskontrolle). $\mathrm{O}$ controle de atos ultra vires e o controle de identidade podem ter como resultado a inaplicabilidade do direito europeu na Alemanha. O TCFA deixa, porém, em aberto em qual tipo de procedimento sua jurisdição poderia ser invocada para exercer tal controle. A doutrina entende que a proclamação desses dois tipos de controle do direito europeu pelo TFCA representa uma reação ao ativismo judicial do TJUE presente em decisões controversas recentes ${ }^{31}$.

O TCFA afirma ainda que as novas disposições referentes à alteração dos tratados europeus - a saber, o processo de revisão ordinário (art. 48.2-5 TUE-Lisboa), o processo de revisão simplificado (art. 48.6 TUE-Lisboa), as chamadas "cláusulas-ponte" (a cláusula-ponte geral do art. 48.7 TUE-Lisboa e a cláusula-ponte especial do art. 81.3 TFUE $^{32}$ e a cláusula de flexibilidade (art. 352 TFUE) ${ }^{33}$ - não são contrárias à soberania estatal, pois entende que as instituições da UE não podem independentemente alterar as fundações da União e seus tratados ${ }^{34}$.

Porém, segundo o TCFA, o exercício desses instrumentos exige uma lei de acordo com o art. 23 I 2 e 3 LF ou a aprovação do Parlamento alemão, além do consentimento do Conselho Federal, se este for necessário segundo a legislação nacional. Com isso, o Tribunal exclui a possibilidade de a União ampliar suas competências por conta própria. Qualquer passo significativo em direção à extensão das competências da UE - por exemplo, a mudança da unanimidade para a maioria qualificada na votação no Conselho ou o recurso à cláusula de flexibilidade do art. 352 TFUE - deverá ser antes submetido à aprovação do Parlamento e do Conselho Federal na Alemanha, uma vez que apenas o consentimento do governo não cumpre as exigências da legitimidade democrática ${ }^{35}$.

${ }^{31}$ Vale observar que na decisão Lisboa a relação de cooperação com o TJUE - expressamente mencionada na sentença Maastricht - não é suscitada quando o TCFA discursa sobre sua função de controle de atos ultra vires e do respeito à identidade constitucional. Cf. BVerfG, 2 BvE 2/08, par. 240-241 e WOHLFAHRT, op. cit., p. 1282.

${ }^{32}$ As chamadas cláusulas-ponte permitem alargar o voto por maioria qualificada aos casos sujeitos a uma votação por unanimidade. Conforme o art. 48.7 TUE-Lisboa, no caso de processo de revisão simplificado (cláusulaponte) do novo TUE, os parlamentos nacionais podem notificar sua oposição no prazo de seis meses após a comunicação sobre a revisão prevista. Todavia, o TCFA entende que isso não equivale suficientemente à exigência da ratificação e, por isso, o consentimento pelo representante do governo alemão sempre requererá uma lei nos termos do art. 23 I 2 e, caso necessário, 3 LF.

${ }^{33}$ De acordo com o art. 352 TFUE, se uma ação da União for considerada necessária, no quadro das políticas definidas pelos Tratados, para atingir um dos objetivos estabelecidos pelos Tratados, sem que estes tenham previsto os poderes de ação necessários para o efeito, o Conselho, deliberando por unanimidade, sob proposta da Comissão e após aprovação do Parlamento Europeu, adotará as disposições adequadas. O TCFA considera esta regra como uma ampliação da competência da União, visto que ela serve para criar uma competência, a qual possibilita uma ação em nível europeu em quase toda a área de aplicação do direito primário. Cf. BVerfG, 2 BvE 2/08, par. 327 .

\footnotetext{
${ }^{34}$ Ibid., par. 306-307.

${ }^{35}$ Ibid., par. 319.
} 
Com base neste argumento o TCFA declarou a inconstitucionalidade do art. $1 \S$ $4.3 n^{\circ} 3$ da Lei de Ampliação. Segundo o Tribunal, a referida lei violava o art. 38 I combinado com o art. 23 I LF, dado que ela não assegurava uma participação satisfatória às câmaras parlamentares alemãs nos processos legislativos da UE e nos processos de revisão dos Tratados $^{36}$.

Por fim, o Tribunal confirma a preservação da soberania estatal com fundamento no direito dos Estados-membros de retirada da UE (agora codificado no art. 50 TUELisboa) e no direito de decisão final que cabe ao próprio TCFA ${ }^{37}$.

\subsection{As responsabilidades e competências de peso substancial do Parlamento alemão}

Em conformidade com sua jurisprudência fixada na decisão Maastricht, o TCFA esclarece que o Parlamento alemão, em sua qualidade de representante do povo, e o Governo Federal devem reter uma influência formativa no que se refere a desenvolvimentos políticos na Alemanha ${ }^{38}$.

Porém, ao contrário de sua posição na sentença Maastricht - na qual afirmou de forma bastante geral que as funções e os poderes de substancial importância teriam que permanecer com o Parlamento alemão ${ }^{39}$ - o Tribunal define na decisão Lisboa áreas específicas que devem permanecer, de forma substancial, sob a competência do Parlamento alemão, em vez de concentrar seu argumento em diferentes mecanismos que podem resguardar as competências do Parlamento, como os princípios da atribuição de competências, da subsidiariedade e da proporcionalidade.

Essas áreas de ação formativa democrática incluem as decisões sobre: a cidadania, o monopólio civil e militar do uso da força, as finanças e os gastos públicos, incluindo o financiamento externo, o direito penal formal e material e questões culturais de particular importância, como o uso da língua, o direito de família, o sistema escolar e educacional e o trato com comunidades religiosas ${ }^{40}$.

Após o exame detalhado de diversos domínios, nomeadamente, o direito penal, a cooperação judiciária em assuntos civis e administração na justiça, a política comercial comum, o emprego das Forças Armadas no exterior e a política social, o TCFA concluiu que o Parlamento alemão ainda retém responsabilidades e competências próprias de peso suficientemente substancial ${ }^{41}$.

\footnotetext{
${ }^{36}$ Ibid., par. 409.

${ }^{37}$ Ibid., par. 299.

${ }^{38}$ Ibid., par. 246.

${ }^{39}$ BVerfGE 89, 155, par. 186.

${ }^{40}$ BVerfG, 2 BvE 2/08, par. 249ss.

${ }^{41}$ Ibid., par. 275.
} 


\subsection{Outros pontos importantes da decisão}

A participação das Forças Armadas em operações militares da UE

De acordo com o Tratado de Lisboa, o Conselho da UE decide sobre a participação das Forças Armadas nacionais em operações militares da União. No entanto, para o TCFA, essa regra não significa que o Tratado transfere à UE a competência de recorrer às Forças Armadas dos Estados-membros sem a aprovação dos respectivos países ou de seus parlamentos.

A redação e a história do art. 42 TUE-Lisboa mostram que os Estados-membros queriam continuar detendo a decisão final sobre a participação em uma operação militar ${ }^{42}$. Por isso, com a entrada em vigor do Tratado, subsiste a reserva parlamentária constitutiva com relação às operações das Forças Armadas alemãs no exterior. O TCFA esclarece, portanto, que somente o Bundestag está autorizado a decidir sobre a participação das Forças Armadas alemãs em uma operação militar da UE.

\section{A primazia do direito comunitário}

Aqui cumpre observar a interpretação do TCFA relativa à primazia do direito da União sobre o direito nacional expressamente prevista na Declaração Nr. 17 do Tratado de Lisboa. Segundo o Tribunal, o fundamento e os limites para a aplicação do direito da União na Alemanha continuam sendo a ordem de execução contida na lei de aprovação dos Tratados. Desse modo, não importa se a primazia de aplicação do direito da União já reconhecida fundamentalmente pelo TCFA - é prevista nos próprios Tratados ou na Declaração Nr. 17 incluída nas atas finais do Tratado de Lisboa ${ }^{43}$.

\section{CONCLUSÕES}

Os principais resultados da decisão Lisboa podem ser resumidos como a seguir:

1. Apesar de o Tratado de Lisboa conceder personalidade jurídica própria à União, o TCFA não reconhece a UE como Estado próprio.

2. A LF não permite a participação da Alemanha em uma federação europeia de Estados.

3. O TFCA considera que existe um déficit democrático estrutural no âmbito da UE e, por isso, os direitos de participação do Parlamento alemão devem ser fortalecidos em nível nacional, a fim de garantir a eficácia do direito de voto dos cidadãos alemães e o respeito pela UE das competências que lhe foram outorgadas.

\footnotetext{
${ }^{42}$ Ibid., par. 381 ss.

${ }^{43}$ Ibid., par. 343.
} 
4. Com o objetivo de justificar a expansão da interferência do Parlamento alemão na ação do governo em assuntos europeus, o Tribunal introduz o conceito de "responsabilidade com a integração" (Integrationsverantwortung), constituindo um dos termos-chave da decisão.

5. Mesmo após a entrada em vigor do Tratado de Lisboa, o TCFA continuará exercendo uma função de controle do direito europeu, para salvaguardar o direito democrático de autodeterminação do povo alemão. Nesse sentido, o Tribunal reafirma seu direito de verificar se os atos jurídicos da UE são compatíveis com a LF ou se ultrapassam os direitos de soberania conferidos pela Alemanha. Além disso, alarga sua função de controle, reivindicando um direito de verificar se os atos jurídicos da EU violam a identidade da ordem constitucional alemã considerada como inviolável pelo art. 79 III LF. Tanto o desrespeito dos limites da transferência de direitos de soberania como uma violação da identidade constitucional nacional têm como consequencia a declaração de inaplicabilidade dos respectivos atos jurídicos da UE no direito alemão.

Em suma, a lei de aprovação do Tratado de Lisboa está em conformidade com os requisitos da LF, em especial com o princípio democrático. Logo, o direito de voto segundo o art. 38 I LF não é violado pelo Tratado. Da mesma forma, não há qualquer restrição constitucional contra a Lei que altera a Lei Fundamental. Em contrapartida, o Tribunal declarou a inconstitucionalidade da Lei de Ampliação, na medida em que ela não conferia a esses órgãos constitucionais direitos de participação satisfatórios nos processos legislativos da UE e nos processos de revisão dos tratados europeus ${ }^{44}$.

Por conseguinte, os instrumentos de ratificação do Tratado de Lisboa poderiam ser depositados somente após a alteração e a entrada em vigor da Lei de Ampliação. Em 8 de setembro de 2009 o Parlamento alemão aprovou as novas leis complementares ao Tratado ${ }^{45}$. Em 25 de setembro de 2009 a Alemanha ratifica finalmente o Tratado de Lisboa.

O TCFA decidiu, portanto, pela constitucionalidade do Tratado, mas com a condição de que as competências do Parlamento e do Conselho Federal sejam fortalecidas

${ }^{44}$ Ibid., par. 273-274.

${ }^{45}$ No dia 18 de setembro de 2009 foi a vez do Conselho Federal alemão aprovar tais leis. As leis complementares ao Tratado de Lisboa implementam as recomendações do TCFA, com o objetivo de garantir uma participação satisfatória do Parlamento alemão nos processos legislativos da UE e nos processos de revisão dos tratados europeus. As leis regulamentam também as modificações constitucionais necessárias à ratificação do Tratado e a cooperação entre o Parlamento e o governo alemão em assuntos ligados à UE. No futuro, o governo alemão deverá informar ao Parlamento alemão, de forma antecipada, sobre todos os projetos referentes à UE. 
em nível nacional. Assim, não exigiu nenhuma alteração do Tratado para sua ratificação, mas sim da lei interna sobre os direitos de participação das duas câmaras legislativas alemãs no processo de integração europeia.

Para finalizar cabe uma breve avaliação geral da decisão Lisboa do TCFA. Esta representa essencialmente uma continuação da sentença Maastricht. Ela reafirma os pressupostos e limites da integração fixados na decisão de 1993, mas inova por fornecer importantes esclarecimentos, como, por exemplo, sobre o conceito de associação de Estados (Staatenverbund) e definir as áreas que devem permanecer, de forma substancial, sob a competência do Parlamento alemão.

Seguindo também a sentença Maastricht, o TCFA reafirma seu direito de verificar se os atos jurídicos da UE são compatíveis com a LF ou se ultrapassam os limites da transferência de direitos de soberania fixados na lei de aprovação. Contudo, na decisão Lisboa o TCFA vai além e alarga sua função de controle, reivindicando um direito de verificar se os atos jurídicos da EU violam a identidade da ordem constitucional alemã. Deste modo, o Tribunal sublinha seu papel de guardião do núcleo inviolável da Lei Fundamental dentro do processo de integração europeia.

Até agora o TCFA não exerceu sua função de controle sobre o direito europeu postulada nas decisões Maastricht e Lisboa e, com isso, evita potenciais conflitos com o TJUE - ainda que o Tribunal alemão tenha alargado em determinada medida seu direito de controle sobre os atos jurídicos na decisão Lisboa.

Outra característica comum entre as decisões Maastricht e Lisboa é o tom de desconfiança por parte do TCFA com relação ao governo federal e ao processo de integração como um todo. Isso explica a exigência presente nas duas decisões de fortalecer a participação dos parlamentos nacionais no âmbito da UE. Explica também a linha de defesa construída pelo Tribunal contra qualquer tipo de transgressão à soberania nacional, ao determinar (na decisão Lisboa) que certas áreas devem permanecer sob a competência do Bundestag. Em conformidade com isso, o TCFA postula o direito de controlar se a União observa o padrão alemão de proteção dos direitos fundamentais, os limites da delegação dos direitos de soberania e a identidade constitucional dos Estados-membros.

Em ambas as decisões - Maastricht e Lisboa - um ativismo judicial é manifestado pelo TCFA. Assim, o Tribunal não se restringiu a verificar a compatibilidade dos respectivos Tratados com a Constituição alemã, indo além, com a formulação de declarações sobre a a participação da Alemanha na UE, conectadas a várias advertências, restrições e reservas. Esse comportamento pode ser criticado, na medida em que representa uma intromissão na competência preponderantemente exclusiva do governo de conduzir a política europeia da Alemanha ${ }^{46}$.

\footnotetext{
${ }^{46}$ Cf. KÖNIG, op. cit., p. 28-29.
} 
Nesse contexto, cumpre destacar a determinação do TCFA na decisão Lisboa, segundo a qual o consentimento do representante alemão no Conselho, relativo às decisões europeias que dizem respeito à soberania nacional, tais como decisões sobre a política exterior e de defesa, depende da aprovação prévia do Parlamento alemão. Aqui o ativismo judicial do TCFA pode ser criticado, uma vez que ele pode causar uma limitação da liberdade de ação do governo no âmbito da UE. Como consequência da decisão Lisboa, por exemplo, rápidas operações militares pela UE com a participação das Forças Armadas alemãs serão, na prática, de difícil execução, visto que o governo federal deverá toda vez antes de uma decisão do Conselho sobre o envio de tropas da UE obter a aprovação do Parlamento alemão.

No final, as decisões Maastricht e Lisboa enviam a mesma mensagem: a Lei Fundamental é favorável à participação alemã no processo de integração europeia. Logo, o TCFA defende o princípio da abertura da Constituição alemã ao direito europeu (Europarechtsfreundlichkeit). Porém, a UE não pode evoluir às custas da soberania da República Federal da Alemanha. Disso resulta-se que um programa integracionista é admissível exclusivamente segundo o princípio da atribuição de competências, o qual garante o respeito da identidade constitucional dos Estados-membros e a capacidade desses de organizar, de forma autoresponsável, no âmbito político e social, as relações de vida de seus cidadãos ${ }^{47}$.

\section{REFERÊNCIAS}

KÖNIG, Doris. Das Urteil des Bundesverfassungsgerichts zum Vertrag von Maastricht - ein Stolperstein auf dem Weg in die europäische Integration? Zeitschrift für ausländisches öffentliches Recht und Völkerrecht (ZaöRV), v. 54, 1994. pp. 17-94.

SCHWEITZER, Michael. Staatsrecht III. 9. ed. Heidelberg: Müller, 2008.

STEIN, Torsten; VON BUTTLAR, Christian. Völkerrecht. 12. ed. Colônia: Heymann, 2009.

STREINZ, Rudolf. Europarecht. 8. ed. Heidelberg: Müller, 2008.

TOMUSCHAT, Christian. The Ruling of the German Constitutional Court on the Treaty of Lisbon. German Law Journal, v. 10, 2009, pp. 1259-1262.

WOHLFAHRT, Christian. The Lisbon Case: A Critical Summary. German Law Journal, v. 10, 2009. pp. 1277-1286. 